\title{
Information, similarity and vocalization in free learning of numbers
}

\section{STEFAN SLAK, University of Toledo, Toledo, Ohio 43606}

Thirty-two Ss were given a free learning task involving either high-similarity-low-information quinary numbers or lowsimilarity-high-information decimal numbers. Reading of the items was either silent or vocalized. The design was a 2 by 2 factorial. Quinary numbers were more difficult to learn. Vocalization resulted in slower learning. There was no interaction. Decimal code was interpreted as superior to the quinary code.

Miller (1956) pointed out that memory span is limited by the number of items and varies with the amount of information contained in each item. Memory storage of high information items is, therefore, more efficient in informational terms than storage of low information items, though the number of items in the memory store is the same.

The purpose of the present study is to extend the problem to a free-learning situation, with quinary digit groups as low-information and decimal numbers as high-information items. It is predicted that decimal items will not be harder to learn than quinary items though representing higher information content. It is further predicted that decimal items will be easier to learn than quinary items because of lower interitem similarity. The higher the information content of a unit, the lower is its relative frequency of occurrence and the lesser is the similarity of items composed of those units. Interitem similarity has a known negative effect on free recall (Stimmel \& Stimmel, 1967) and learning (Underwood, 1952).

The prediction will be tested under two conditions of vocalization: silent and vocalized reading of items.

$$
\text { METHOD }
$$

Thirty-two Ss, students in introductory psychology classes, were randomly assigned to different experimental conditions.

An adjustable-rate memory drum was used for presentation of the items with a screen separating the $S$ from the $E$.

Sixteen different lists were used. Each list consisted of eight three-place numbers in 10 different random orders. The items were typed on a memory tape. Eight lists were composed of decimal digits and the other eight of quinary digits. In a decimal list, each item consisted of a random permutation of 10 digits taken 3 at a time. In a quinary list, an item was a random permutation of a selection of 5 digits taken 3 at a time. Four selections of quinary digits were used, each one assigned to an equal number of different Ss: (1) all even digits including zero, (2) all odd digits, (3) the first 5, and (4) the last 5 digits. Two different lists were composed of each selection of quinary digits.

Each $S$ was tested on one of the 16 lists. A trial consisted of a presentation and a reproduction period. During the presentation period, the $S$ was presented with the eight items of the list at a 2 -sec rate. In each trial the same list was presented in a different order. The same orders were repeated in blocks of 10 trials. In the reproduction period of each trial, the $\mathrm{S}$ had $30 \mathrm{sec}$ to reproduce the items in any order, with a 30 -sec rest period between the end of reproduction and the onset of the next trial.

Sixteen Ss were given the decimal list and 16 the quinary list. Four Ss were tested on each of the four selections of
Table 1

Means of Trials-to-Criterion for the Four Experimental Conditions

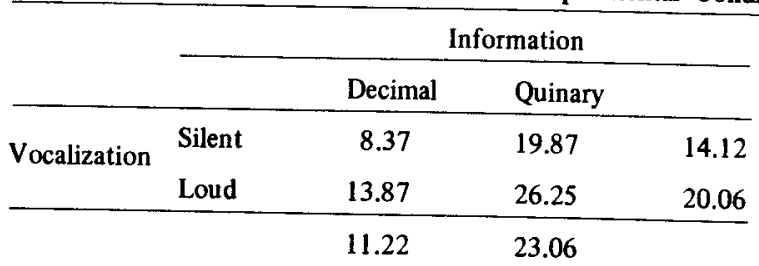

quinary digits. Two Ss were tested on each of the 16 lists, one under each of the two vocalization conditions, namely either silent or vocalized reading of the items. This corresponds to 2 by 2 factorial design with factors of Information (I) and Vocalization (V).

\section{RESULTS}

The raw score was the number of trials to criterion. Because of marked positive skewness the log transformation of raw scores was used, resulting in a rather normal distribution and homogeneity of variance $(\mathrm{Fmax}=6.153, \mathrm{p}>.05)$.

The means of nontransformed raw scores (see Table 1) suggest strong effects of Information and Vocalization. An analysis of variance shows both factors to be significant (Information: $F=11.03, \mathrm{df}=1 / 28, \mathrm{p}<.01$; Vocalization: $\mathrm{F}=5.13, \mathrm{df}=1 / 28, \mathrm{p}<.05$ ) with virtually no interaction between the two factors.

\section{DISCUSSION}

Greater information content of decimal items did not interfere with learning. On the contrary, lower interitem similarity of decimal items resulted in faster learning. A greater amount of information was learned faster than a lesser amount. This indicates superiority of a decimal digit code over a quinary code, since the numbers could represent any source of information. Memory storage of numerically coded information seems to be more efficient, if information content per digit is high.

The effect of overt vocalization was to increase the overall difficulty. This is not consistent with previous findings. Murray $(1965,1967)$ found that overt vocalization is positively related to recall. Further clarification is needed before an explanation of this inconsistency can be offered.

\section{REFERENCES}

MILLER, G. A. The magical number seven plus or minus two: Some limits on our capacity for processing information. Psychological Review, 1956, 63, 81-97.

MURRAY, D. J. Vocalization-at-presentation and immediate recall, with varying presentation rates. The Quarterly Journal of Experimenta Psychology, 1965, 17, 47-56.

MURRAY, D. J. The role of speech responses in short term memory. Canadian Journal of Psychology, 1967, 21, 263-276

STIMMEL, D. T., \& STIMMEL, N. S. Free recall as a function of intralist similarity and order of presentation constraints. Psychological Reports, 1967, 21, 541-544.

UNDERWOOD, B. J. Studies of distributed practice: VII. Learning and retention of serial nonsense lists as a function of intralist similarity. Journal of Experimental Psychology, 1952, 44, 80-87. 